\title{
Venting of Deflagrations: Dynamics of the Process in Systems with a Duct and Receiver
}

\author{
VLADIMIR V. MOLKOV \\ All-Russian Research Institute for Fire Protection \\ VNIIPO, Balashikha-3, Moscow region, 143900 Russia
}

\begin{abstract}
This paper describes the application of a proposed model to vented gaseous explosions in a small and large-scale equipment with venting of deflagration through exhaust duct to receiver or atmosphere. It was shown that introduction of a duct and vacuumed receiver into explosion protection system can have strong influence on dynamics of vented deflagration and increase of maximum explosion pressure. The physics of this phenomenon was studied. Coincidence between values of the main unknown parameter of the vented combustion process model turbulization factor $\chi$ from this work and results following from K.I. Shchelkin and B. Karlovits theories was obtained and confirmed by cinegrams. The 3.7-4 times growth of burnout rate in the vessel due to high level turbulence combustion in the duct was determined by inverse problem method. The discovered effect of combustion intensification can be removed by increase of vent relief pressure or sprinkling of cooling agent into gas mixture flow at the beginning of a duct.
\end{abstract}

KEYWORDS: venting of deflagration, dynamics, inverse problem method, turbulisation factor, small and large-scale experiments, vent relief pressure, cooling agent

\section{INTRODUCTION}

Venting of deflagration is defined as the main protection method against explosions within process equipment and industrial rooms. The idea of this method consist in a restriction of explosion overpressure to permissible levels due to the efflux of gaseous products through the vent of a sufficient area during explosions. But sometimes, for example in the case of toxic substances, when there is a high occupational and ecological danger, or if you want to prevent secondary fires and explosions in industrial rooms after the initial explosion within equipment 
you can not discharge high temperature burnt gases and technological substances from equipment into the atmosphere.

There are a few data about the influence of an exhaust duct on explosion dynamics, for example $[1,2]$. The problem of influence of receivers is not studied practically.

\section{MODEL}

Because of receiver availability, gaseous products flow from an explosion vessel to the space with an increasing pressure. Let us consider the ideal gas flow from the vessel of a volume $V$ with pressure $p$ and gas density $\rho$ to the receiver of a volume $V_{r}$ with pressure $p_{r}$. The energy conservation law for the receiver in the case of a disregard of heat exchange with an environment will be written in the form [3]

$h \cdot d m=d\left(m_{r} \cdot u\right)$

where $h=$ enthalpy per mass unit for gas, which flows into the receiver, $\mathrm{J} / \mathrm{kg} ; d m=$ increase of gas mass, $\mathrm{kg} ; m_{r}=$ gas mass inside the receiver, $\mathrm{kg} ; u=$ internal energy per mass unit inside the receiver, $\mathrm{J} / \mathrm{kg}$.

After differentiation of equation of state $m \cdot d T=(V \cdot d p+p \cdot d V) \cdot M / R-T \cdot d m$, with taking into account well-known relations $h=C_{p} T ; u=C_{v} T_{r} ; R / M=C_{p}-C_{v} ; \gamma=C_{p} / C_{v}$ we can get the rate of change in receiver pressure

$\frac{d p_{r}}{d t}=\gamma \frac{p}{\rho} \frac{G}{V_{r}}$

where $G=$ mass rate of flow, $\mathrm{kg} / \mathrm{s} ; \gamma=$ ratio of specific heats of the flowing gas.

There may be two extreme situations when unburnt and burnt gases flow from the vessel, in which deflagration occurs, to the receiver: 1) rapid burnout of unburnt gas inside the duct and/or the receiver as a result of intensive turbulent mixing with high temperature combustion products (burnt gas); 2) "freezing" of unburnt and burnt gas mixture due to cooling, phlegmatization and/or inhibition in the beginning of the duct. We need also to account pressure change because of heat losses to duct and receiver walls, and in some cases (with sprinkling of a gas flow) because of additional mass of gases due to evaporation of a cooling agent.

As a result of above-mentioned the equation (2) can be written in the next form

$\frac{d p_{r}}{d t}=\xi\left[K \gamma_{u} \frac{(1-A) G_{u}}{\rho_{u}}+\gamma_{b} \frac{A G_{b}}{\rho_{b}}\right] \frac{p}{V_{r}}$

where $K=$ coefficient, taking into account a burnout of a combustible (unburnt) gas inside the duct and the receiver; $\xi=$ coefficient, taking into account an influence of a heat and mass exchange inside the duct and the receiver on a value of pressure; $A=$ venting area part occupied by combustion products at a given moment; subscripts " $u$ " and "b" refer to unburnt and burnt gases respectively. We used approximations: $A=\left(r_{b} / a\right)^{2}$, where $r_{b}$-flame radius and $a$-vessel radius, for central ignition and small pressure at which venting begins; $A=1$ for ignition near vent, for "high" relief pressures, for systems with a duct without sprinkling [4]. 
Burnout coefficient $K$ as a matter of fact is equal in mentioned above extreme situation 1) to combustion products expansion coefficient and for majority of stoichiometric hydrocarbon-air mixtures can be taken as 7.3 with error not more then $10 \%$ for research ranges of pressures and temperatures. In another extreme situation 2) with "freezing" $K$ is equal 1 . The value of thermokinetic factor $\varepsilon$ in the dependence of burning velocity from explosion pressure was taken as $\varepsilon=0.24$ in this work. The values of adiabatic indices for unburnt and burnt stoichiometric acetone-air mixture, that had been used in the experiments, equal respectively $\gamma_{4}=1.36$ and $\gamma_{b}=1.24$; combustion products expansion coefficient at initial pressure $E_{i}=7.96$. These values were used in theoretical simulations of the experiments.

The set of dimensionless differential equations of deflagration dynamics in the vessel, with simultaneous efflux of explosion products into the receiver with different initial pressures, is given in paper [5].

This set of equations can be applied to "short" ducts only, for which its length $L_{d} \leq 0.1 C t_{e}$, where $t_{e}$ - time from the moment of venting beginning until the moment of combustion completion in a vessel, $C$ - the speed of sound in a flowing mixture.

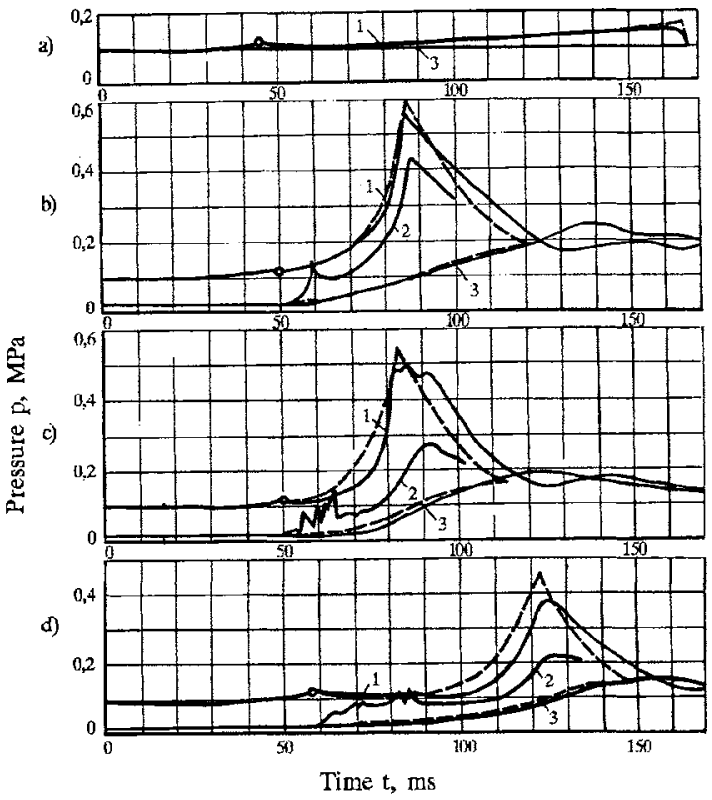

FIGURE 1. Explosion dynamics in a $0.027 \mathrm{~m}^{3}$ vessel with low venting pressures: a) - efflux directly into the atmosphere (test N1 in Table 1) ; b), c), d) - efflux through the duct into the receiver (tests $\mathrm{N} 2-4$ in Table 1 ); - experiment; - - - calculation; (1 - vessel, 2 - duct, 3 - receiver or atmosphere); o - the beginning of venting. 


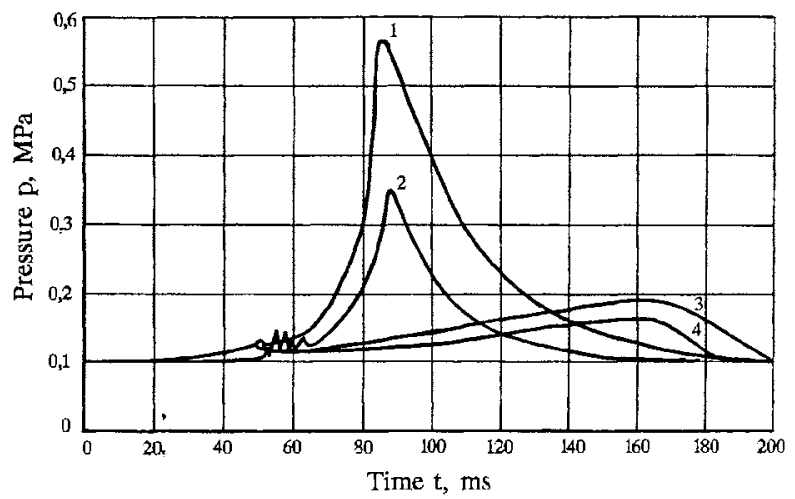

FIGURE 2. Explosion dynamics in a $0.027 \mathrm{~m}^{3}$ vessel, equipped with a duct (diameter $5 \mathrm{~cm}$, length $183 \mathrm{~cm}) ; 1,2$ - pressures respectively in the vessel and in the duct without sprinkling of gas flow in the duct; 3 - pressure in the vessel (with sprinkling of gas flow in the duct); 4 pressure in the vessel (without the duct); o- the beginning of venting.

\section{SMALL-SCALE AND LARGE-SCALE INVESTIGATIONS}

Experiments were made on small-scale and large-scale installations. Near-stoichiometric air mixtures of acetone were used for deflagration in the vessel. Receiver contains just air. The initial pressure was $p_{i}=0.1 \mathrm{MPa}$ in the explosion vessel and $p_{r}=0.02 \mathrm{MPa}$ for the most cases in the receiver. Vent was covered by a rupture disk in both the small-scale and large-scale tests. These experiments show, that an introduction of the duct and the receiver (see, for example, Figure 1) or only the duct (Figure 2) into the protection system changes the explosion dynamics essentially. It is accompanied by a strong increase in a maximum explosion pressure. What is the reason of a such powerful changes in explosion dynamics and a strong increase in a maximum explosion pressure?

\section{Small-Scale Research}

Experimental pressure-time curves in vessels and receivers were processed by inverse problem method with the use of earlier offered theory and mathematical model, the system of dimensionless differential equations of which is cited in the previous paper. ${ }^{2}$ Results of such processing are values of: turbulization factor $\chi$, which is equal to the ratio of a real turbulent flame front area to spherical laminar flame front area for the same amount of a burnt gas; discharge coefficient $\mu$; coefficient $\xi$ taking into account heat mass exchange in a receiving space (duct and receiver); initial normal burning velocity $S_{u i}$, which is determined by the use of an initial stage of combustion in the closed vessel. These results are given in Table 1.

It is easy to see, when the efflux from a vessel to a receiver occurs at a low level of venting pressures (see experiments 2.4 on Figure 1) the turbulization factor $\chi$ increases by a factor of 3.7 as compared to the case of efflux through the vent directly into the atmosphere (at the same time the difference in a discharge coefficient $\mu$ is insignificant).

What is the cause of such combustion intensification in the vessel from which explosion products flow? It can be suggested, proceeding from the analysis of pressure-time curves in the vessel 
TABLE 1. Values of turbulization factor $\chi$; discharge coefficient $\mu$; coefficient of heat mass exchange $\xi$ and initial burning velocity $S_{u i}$ for small-scale experiments

\begin{tabular}{|c|c|c|c|c|c|c|c|}
\hline Test number & Water mass, $\mathrm{g}$ & $p_{v}, \mathrm{MPa}$ & $L_{d}, \mathrm{~m}$ & $S_{u i,} \mathrm{~m} / \mathrm{s}$ & $\chi$ & $\mu$ & $\xi$ \\
\hline 1 & no & 0.123 & no & 0.29 & 1 & 0.67 & no \\
\hline 2 & no & 0.120 & 1.83 & 0.26 & 3.7 & 0.63 & 0.57 \\
\hline 3 & no & 0.125 & 2.35 & 0.28 & 3.7 & 0.77 & 0.50 \\
\hline 4 & no & 0.125 & 2.35 & 0.28 & 3.7 & 0.78 & 0.40 \\
\hline 5 & no & 0.265 & 2.35 & 0.29 & 1.7 & 0.93 & 0.40 \\
\hline 6 & no & 0.242 & 1.83 & 0.29 & 1.65 & 0.52 & 0.54 \\
\hline 7 & 140 & 0.140 & 1.83 & - & - & - & - \\
\hline 8 & 25 & 0.140 & 1.83 & 0.26 & 1.15 & 0.43 & 0.30 \\
\hline 9 & 8 & 0.155 & 1.83 & 0.24 & 1.2 & 0.48 & 0.70 \\
\hline
\end{tabular}

The vessel volume is $0.027 \mathrm{~m}^{3}$, the receiver volume is $0.050 \mathrm{~m}^{3}$, the diameter of the vent and the duct is $5 \mathrm{~cm}, p_{v}$ pressure at which venting begins.

and in the duct, that during a short-term period of few milliseconds, when pressure in the duct higher then it is in the vessel, the inverse discharge of reacting gas from the duct into combustion products within the vessel turbulizes the flame front and further development of explosion occurs under turbulization conditions.

This suggestion was fully confirmed by cinegrams of process development within the vessel and the duct (Figure 3). You can see from the cinegram, that after the period of spherical flame propagation in the closed vessel venting begins. Both an unburnt gas and a high temperature burnt gas flow into the duct. Their mixing under intensive turbulence can lead to cooling of burnt gas (decrease of visible radiation) and to heating of unburnt gas in the beginning and some time later to intensive volume exothermic reaction, which gives the short-term pressure peak higher than pressure in the vessel. It is accompanied by reacting mixture jet from duct into combustion products within the vessel (with the velocity approximately $200 \mathrm{~m} / \mathrm{s}$ ). And, as you can see from the cinegram (Figure 3), this jet turbulizes the combustion of unburnt gas within the vessel.

Let us compare results obtained above with the conclusions of turbulent combustion theory. According to K.I. Shchelkin theory [6], the turbulent burning velocity is approximately equal to the pulsating velocity $S_{t} \approx v^{\prime}$ at fairly high ratios $v^{\prime} / S_{u}$. On the other side, B. Karlovits and colleagues [7] obtained for a turbulence, generated by the turbulent front itself, the next appraisal for the maximum pulsating velocity $v^{\prime}=S_{u}\left(E_{i}-1\right) / \sqrt{3}$, that gives $\chi=3.5-4$ for nearstoichiometric carbonhydrogen-air mixtures. It is in a good agreement with value $\chi=3.7$, obtained in small-scale experiments without sprinkling of flowing explosion products in the duct, when the flame front in the vessel is turbulized by a short-term inverse reacting gas discharge from the duct inside the combustion products within the vessel (the analogy to a turbulence, generated by the flame front itself in terms of $\mathrm{B}$. Karlovits model).

So far as conclusions of K.I. Shchelkin and B. Karlovits theories do not depend on scale factor, we can expect the same result (in the sense of the same values of turbulization factor $\chi$ ) for large-scale experiments. 

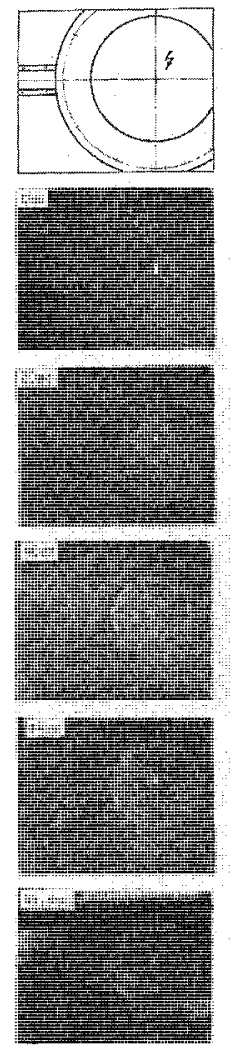
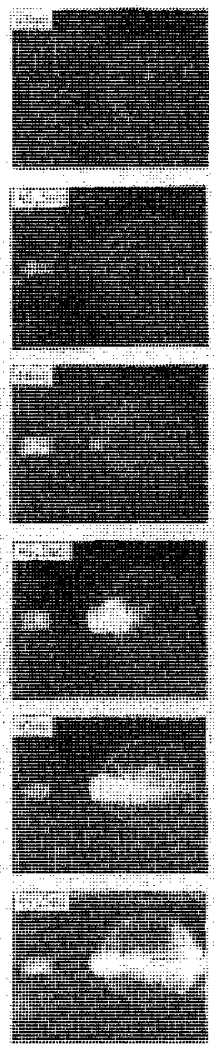
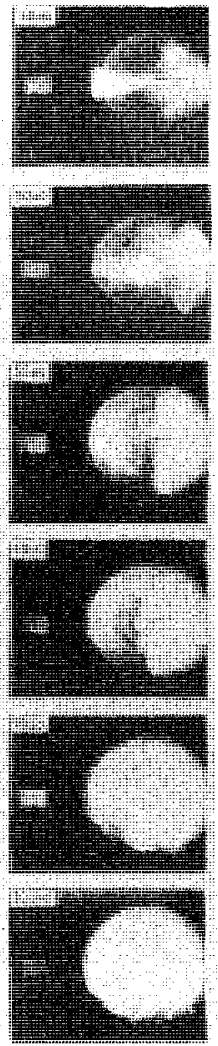

FIGURE 3. The cinegram of an explosion process in $0.027 \mathrm{~m}^{3}$ vessel and initial part of the duct (efflux into receiver without sprinkling of gas flow by cooling agent): numbers on the cinegram $=$ milliseconds from the beginning of the process.

\section{Large-Scale Research}

There are typical experimental oscillograms for large-scale equipment in Figure 4. Results of their processing by the inverse problem method are given in Table 2 . One can determine from Figure $4 \mathrm{a}$, that after vent cover rupture there is a shock wave spreading with a velocity near $500 \mathrm{~m} / \mathrm{s}$ over the duct. The gas flow velocity behind the shock wave front is equal to $V_{8}=\left(p_{2}-p_{1}\right) /\left(V_{w} \rho\right)$, where $V_{w}$ - shock wave velocity, subscripts 1 and 2 refer to gas parameters before and after shock wave front. Thus the gas flow velocity in the duct is near $200 \mathrm{~m} / \mathrm{s}$.

The large-scale research affirms results of the small-scale research and statements of K.I. Shchelkin and B. Karlovits theories. Some larger value of turbulization factor $\chi=4$ for experiments with sprinkling in a large-scale equipment accords to the known statement about the growth of a turbulization degree with the increase of problem characteristic size (Reynolds number). 


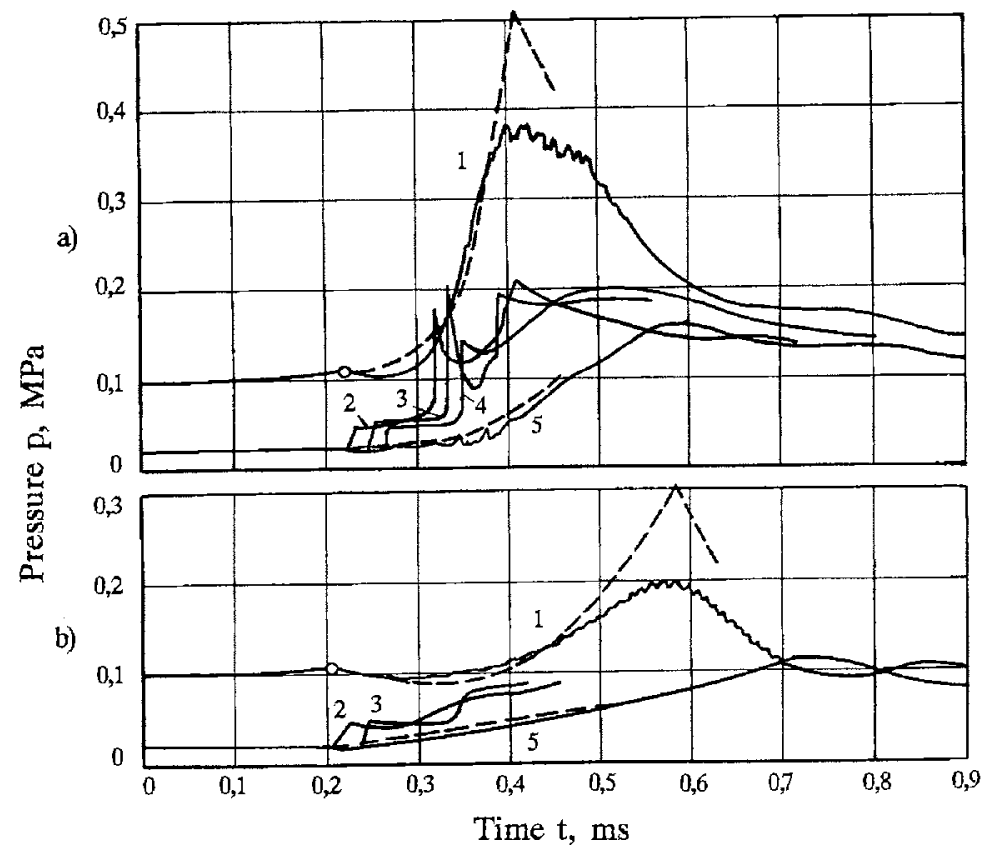

FIGURE 4. Explosion dynamics in a $10 \mathrm{~m}^{3}$ vessel (1), the duct (2-4 - respectively on the distance $1.5 ; 11.5$ and $21.5 \mathrm{~m}$ from the vessel) and $12 \mathrm{~m}^{3}$ receiver (5): a) - without sprinkling of gas flow in the duct; b) - with sprinkling of gas flow in the duct; - _ - experiment; - - - calculation; $\circ$ - the beginning of venting.

TABLE 2. Values of turbulization factor $\chi$, discharge coefficient $\mu$; coefficient of heat mass exchange $\xi$; initial burning velocity $S_{u i}$ for large-scale experiments (Figure 4)

\begin{tabular}{cccccccc}
\hline Test number & Water & $p_{v}, \mathrm{MPa}$ & $L_{d}, \mathrm{~m}$ & $S_{u i}, \mathrm{~m} / \mathrm{s}$ & $\chi$ & $\mu$ & $\xi$ \\
\hline 1 & no & 0.110 & 25 & 0.32 & 4 & 0.99 & 0.35 \\
2 & yes & 0.105 & 25 & 0.30 & 2.5 & 0.99 & 0.35 \\
\hline \hline
\end{tabular}

The vessel volume is $10 \mathrm{~m}^{3}$ (vertical cylinder with $L: D=5: 1$ ), the receiver volume is $12 \mathrm{~m}^{3}$, the diameter of the vent and the duct is $50 \mathrm{~cm}, p_{\nu}$ - pressure at which venting begins.

\section{DISCUSSION}

An explosion dynamics depends on a venting pressure. When venting pressure exceeds $p_{v}>$ $0.2 \mathrm{MPa}$ (Figure 5) the short-term discharge from the duct into the vessel becomes improbable, because of the decrease of an unburnt gas mass part in a gas mixture which is entering into the duct immediately after the vent cover rupture. Turbulization factors for these experiments $\chi=1.65-1.7$. It is slightly higher than typical values $\chi=1-1.5$, obtained for explosion products efflux from the vessel of the same volume directly (without duct) into the atmosphere. Such 


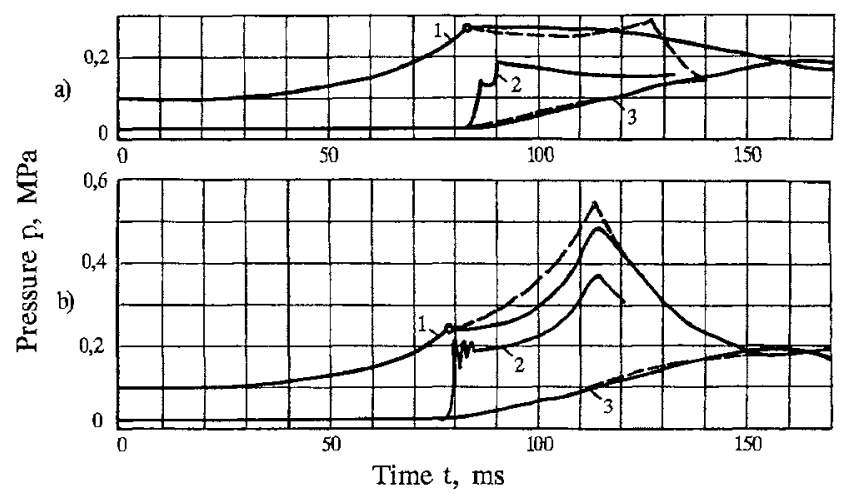

FIGURE 5. Explosion dynamics in a $0.027 \mathrm{~m}^{3}$ vessel with respectively high venting pressures: a), b) - tests N5 and N6 respectively (see Table 1); _ _ - experiment; - - calculation; 1 - vessel; 2 - duct; 3 - receiver; $\circ$ - the beginning of venting.

increase in turbulization factor can be explained by some larger pressure difference on a vent cover before venting in the case of vacuumed duct and receiver, and hence by larger disturbing influence of a venting on the flame front. Just as we have expected, the higher the venting pressure is the higher the value of a discharge coefficient $\mu$ (as we know, the higher the gas flow velocity is the higher the value of a discharge coefficient [3]).

The low value of discharge coefficient $\mu=0.52$ in test $N 6$ can be explained by incomplete opening of the vent cover (there is product of vent area and discharge coefficient $\mu . F$ in model equations, but calculations are made with $F=$ const for a series of experiments and incomplete opening of a vent cover is taken into account through the variance of a discharge coefficient, which is determined by inverse problem method). It can be noted, that the use of $\chi=$ const approximation during explosion development describes good enough the real situation for a lot of experiments. In the reality, the value of turbulization factor can both increase (test N3) and decrease (test N5) during one explosion. The main reason of combustion intensification in a vessel is the mixture burnout inside the duct under high turbulence conditions $\left(\operatorname{Re} \cong 10^{6}-10^{7}\right)$.

The influence of a water sprinkling into the burnt and unburnt gas mixture flow inside the duct directly after the vent was studied. Some results of this research are shown in Figure 6 (see Table 1, tests N7-9). Availability of a cooling agent in the duct reduces a maximum explosion pressure practically to a pressure level in the case of venting directly into the atmosphere (compare Figure 6c and Figure 1a). Cinegrams show that in this case there is no inverse discharge of reacting gas from the duct into the vessel, which can turbulize the combustion in the vessel, and a flame front surface remains sufficiently smooth $(\chi=1.2)$. The comedown of a discharge coefficient value to $\mu=0.48$ can be explained by decrease of an effective section area of a duct and a flow velocity because of presence of some mass of water there in the duct (let us remind, that there is $F=$ const in calculations). In test $N 7140 \mathrm{~g}$ of water had been filling the full space between two rupture disks; in test N8 $25 \mathrm{~g}$ of water had been situated in special paper enclosure (thin paper cube without top side); in test N9 $8 \mathrm{~g}$ of water were dispersed into duct 

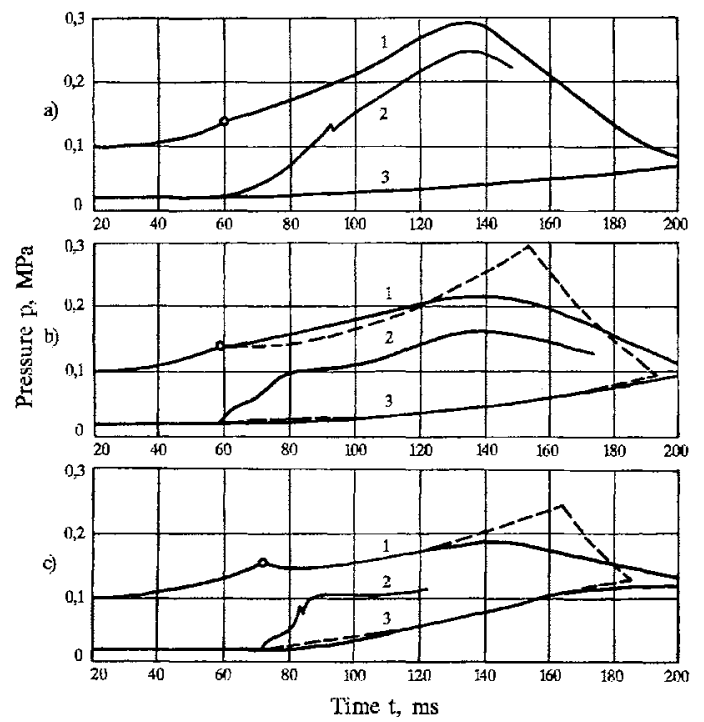

FIGURE 6. Explosion dynamics in a $0.027 \mathrm{~m}^{3}$ vessel with sprinkling of gas flow in the duct: a) - test N7 (140g of $\left.\mathrm{H}_{2} \mathrm{O}\right)$; b) - test $\mathrm{N} 8\left(25 \mathrm{~g}_{\text {of }} \mathrm{H}_{2} \mathrm{O}\right)$; c) - test $\mathrm{N} 9\left(8 \mathrm{~g}\right.$ of $\left.\mathrm{H}_{2} \mathrm{O}\right)$; experiment; - calculation; 1 - vessel; 2 - duct; 3 - receiver; 0 - the beginning of venting.

from hydroimpulse device (based on gun powder energy and piston, pushing water out) directly behind rupture disk just before its opening. It is interesting to note, that in experiments with preliminary filling of duct by water (in special paper enclosure), as in test N8, the value $\xi=0.3$ is less than typical values $\xi=0.4-0.57$ (tests $\mathrm{N} 2-6$ ) for experiments without sprinkling. On the contrary, for a high degree of water dispersion from hydroimpulse device we obtained greater value $\xi=0.7$. It testifies, that when we use a water as a cooling agent in the form of single mass, the cooling decreases the pressure more strongly then the evaporation increases it. From another side we can see, that when we disperse a small amount of water, the pressure increase by reason of mass exchange prevails over the pressure decrease due to heat exchange between high temperature combustion products and water. The quantity and the flow of water influence explosion dynamics. Optimal water flow is $(1-5) \cdot 10^{-3} \mathrm{~m}^{3} /\left(\mathrm{m}^{2} \cdot \mathrm{s}\right)$.

Cinegrams of the process inside the duct allow to understand how a gas flow and liquid are interacted with each other. High speed gas flow tears off small drops from water mass. If a drop size exceeds critical drop size, determined by Weber's criterion $W e=\left(\rho_{g} V^{2} d\right) / \sigma$ (the limit of drop stability $[8,9]$ accords to $\mathrm{We} \cong 10$ ), where $\rho_{g}$ - gas density, $V$ - relative velocity, $d$ - drop diameter, $\sigma$ - surface-tension coefficient, this drop will be crushed into small parts. With the velocity of a relative motion $V=200 \mathrm{~m} / \mathrm{s}$ and $\sigma=72.5 \cdot 10^{-3} \mathrm{~N} / \mathrm{m}$ the critical drop size is near 20 micron. Any drop of greater size will be crushed in the time $\tau=1.65 \frac{d}{V_{o}}\left(\frac{\rho_{l}}{\rho_{g}}\right)^{0.5}$, where $V_{o}-$ initial relative velocity of a drop, $\rho_{l}$ - liquid density. So the drop with 100 micrometers in diameter 
will be crushed into small parts in 25 microseconds, during this period gas phase will move only 5 millimeters.

Thus a turbulent mixing of unburnt and burnt gases entering into the duct from the vessel occur under intensive evaporation of small drops conditions. The temperature of gas mixture decreases, the concentration of aqueous vapor increases. In such conditions the burnout of unburnt gas in the duct becomes impossible.

\section{ACKNOWLEDGMENTS}

The author would like to thank Dr. L.M. Meshman and Dr. V.P. Nekrasov for their help during this work, Prof. A.N. Baratov and Prof. A.Ya. Korolchenko for helpful discussions and unknown reviewer of this article for estimate and interesting comments.

\section{REFERENCES}

1. Heinrich, H.J., "Grenzen der Anwendung der Explosionsdruckentlastung", Schadenprisma, 4, 69-75, 1975 .

2. Molkov, V.V.,Nekrasov V.P. andBaratov, A.N., "About turbulization of combustion when venting of deflagrations", in Proceedings of VIl all-union scientific-practical conference "Combustion and fire fighting problems", Section: Heat transfer in fire, ed. I.I. Petrov, pp.35-37, VNIIPO, Moscow, 1981 (in Russian).

3. Hertz, .V. and Kreinin, G.V., The pneumatic drives dynamics of automat-machines, Machinebuilding, Moscow, 1964.-236p.

4. Baratov, A.N., Molkov, V.V. and Agafonov, V.V, "Combustion of homogeneous gaseous mixtures in vented vessels", ArchivumCombustionis, 8: 2, 179-195, 1988 (in Russian).

5. Molkov, V.V., Baratov A.N. and Korolchenko A.Ya., "Dynamics of Gas Explosions in Vented Vessels: Review and Progress", in Progress in Astronautics and Aeronautics. Volume 154 (Dynamic Aspects of Explosion Phenomena), ed. A.L.Kuhl et al., pp.117131, AIAA, Washington, D.C., 1993.

6. Shchelkin, K.I., "About burning at turbulent flow", Journal of technical physics, 13: 9-10, 520-530,1943.

7. Karlovits, B., Denniston, D.W.Ir. and Wells, F.E., "Investigation of turbulent flames", L. Chem. Phys., 19: May, 541-547, 1951.

8. Rauschenbah, B.V., Beliy, S.A., Bespalov, I.V., Borodachev, V.Ya., Volinskiy, M.S. and Prudnikov, A.G., Physical principles of a working process in combustion cameras of air-jet engines, Machinebuilding, Moscow, 1964,-526p.

9. Honor, A.L., Rivkind, V.Ya., "Drop dynamics", in Totals of science and technology. Mechanics of liquids and gases, 17, 86-159, 1982. 